This is the peer-reviewed but unedited manuscript version of the following article: Rantala, Sala \& Kankare: Teachers' Working Postures and Their Effects on the Voice. Folia Phoniatr Logop 2018;70:24-36 (DOI: $10.1159 / 000487593$ ). The final, published version is available at

\title{
Teachers' working postures and their effects on the voice
}

\author{
Authors: \\ Leena Rantala ${ }^{\mathrm{a}}$, Eeva Sala ${ }^{\mathrm{b}} \&$ Elina Kankare ${ }^{\mathrm{c}}$ \\ ${ }^{\text {a }}$ Faculty of Social Sciences, University of Tampere, Tampere, Finland \\ ${ }^{\mathrm{b}}$ Department of Otorhinolaryngology, Head and Neck Surgery, Turku University Hospital, Turku, \\ Finland \\ ${ }^{\mathrm{c}}$ Department of Phoniatrics, Tampere University Hospital, Tampere, Finland
}

Short title: Effects of postures on voice

\section{Full address of the corresponding author:}

Leena Rantala

Faculty of Social Sciences, Logopedics

33014 University of Tampere

Finland

leena.m.rantala@uta.fi

Tel +358503812039

Key words: voice ergonomics, voice loading, voice symptoms, voice use, working postures 


\begin{abstract}
Objective To evaluate associations between voice and working postures used during teaching. Methods A researcher assessed 30 teachers' typical working postures of the torso, head, shoulders, upper back and arms by observing and/or asking questions about them. Teachers' options to rest and to adjust furniture according to their needs were also elicited. Voice symptoms were evaluated through two self-assessment forms. Fundamental frequency, sound pressure level (SPL) and alpha ratio were calculated from voice samples recorded before, during and after teaching.

Results The head was most typically in an unergonomic posture while speaking (in $60 \%$ of participants). Other frequently used unergonomic postures were hunched upper back (55\%), raised shoulders (46\%) and twisted torso (43\%). Head and torso twisted and arms upheld were associated with specific voice symptoms and head postures and hunched upper back with voice use. The number of postures was also connected with voice use: if the teachers used over three unergonomic postures, their SPL was higher and the voice broke more often than in those with a lower number of postures.
\end{abstract}

Conclusion Unergonomic postures during speaking affect the voice. It is important to evaluate working postures as a part of voice ergonomic assessment in voice patients. 


\section{Introduction}

An ergonomically good posture is not an inherent ability [1]. All parts of the body are connected with each other, thus any force causing a change in one segment will move other segments to compensate for loss of balance in the body $[1,2]$. This especially concerns the human larynx, which is at "the center of a constant battleground between the deep extensor and flexor groups of muscles of the neck and torso" as Rubin et al. [3] graphically describe it. Furthermore, the movements and postures of body segments are inseparable from communication behaviour and voice use and are intrinsic parts of it [4].

In voice therapy, exercises to improve postural alignment are often included in therapy aims. According to a survey, $37 \%$ of speech therapists guide their clients to do these exercises [5], which have been found to improve clients' body balance [6]. However, associations between voice use and speaking postures have been studied only rarely, particularly from the perspective of voice ergonomics. One reason for this may be the lack of practical tools or protocols for assessing working postures, which is also a common problem in the field of general ergonomics [7]. In an attempt to redress this shortcoming in voice ergonomics, we composed a list of the most typical speaking postures and instructions on how to evaluate them. This protocol can be found in the Voice Ergonomic Assessment in Work Environment-Handbook and Checklist (VEAW) compiled by a team of representing different fields of ergonomics and voice care [8]. The VEAW can be used to evaluate risk factors for voice disorders such as background noise, indoor air quality, working postures and practices. The information is gathered by means of observations, asking questions and making measurements. The VEAW was originally developed for the clinical use of occupational health care experts, but it can also be used in research. The assessment procedure has been described in more detail in the article by Rantala et al. [9]. Data for the present study was collected 
from teachers and their classrooms at the same time as the whole voice ergonomic assessment was made. In earlier reports we have analysed the effects of working postures as a single entity $[9,10]$. In the present study, we scrutinized separate postures and their effects in greater detail.

Another reason for studying the effect of working postures on voice is that musculoskeletal disorders are one of the most typical occupational health problems in teachers [11] and these problems are connected to voice symptoms [12]. It has been shown that $67 \%$ of teachers suffer from neck pain, 33\% from upper limb pain, and 30\% from both [13]. Further, upper back (37\%) and lower back pain (44\%) are also typical problems in teachers [14].

Although voice researchers have had no systematic protocols to assess working postures, there are studies assessing the associations between postures and voice use. A survey of 78 female teachers revealed no association between working postures and voice symptoms [15] while studies on 25 dysphonic teachers [16] and 40 elementary school teachers $[9,10]$ revealed that ergonomically undesirable postures exacerbated the severity of voice symptoms and affected voice production.

One of the most typical undesirable head postures people use is thrusting the head forward (Figure 1). This is common, especially among dysphonic teachers: about $75 \%$ use it [16]. When thrusting the head forward or rotating it, one of the most important muscles in play is the sternocleidomastoid muscle [17]. If the muscle is strained, the incidence of voice symptoms increases [16]. It has been claimed that the forward head posture elevates the larynx by shortening the supra hyoid musculature; especially the stylohyoid and the posterior belly of the digastric muscle [18]. These alterations change the shape of the vocal cavity and moreover impair the resonance of the voice [18, 19]. Head thrust forward may also impede the forward movement of the thyroid cartilage, which inhibits the use of high tones and limits the pitch range of the voice $[3,18]$. In the fine adjustments 
of $F_{0}$ it is particularly important for a speaker to be able to move the larynx vertically freely [20, 21].

\section{FIGURE 1 ABOUT HERE}

The ideal body posture for speaking is upright. This allows the internal abdominal organs to sink down with the help of the force of gravity creating more space for breathing movements with higher lung volume [17]. A standing posture commonly used in dysphonic speakers involves the weight being distributed posteriorly: the pelvis is anterior to the torso with increased thoracic kyphosis and to some extent lumber lordosis $[16,22]$. In this posture, the lumbopelvic stabilizing musculature is passive, while in optimal posture it ought to work actively [23]. Straight posture of the pelvis enables proper weight distribution and balance in the body, thereby sustaining an ergonomic position. An upright position also enables the most favourable posture for the head [24].

External factors affecting speakers' postures are the furniture and devices they use. For instance, projectors or smart boards may cause teachers to twist their heads and torsos. Teachers working with young children are at especially elevated risk of low back pain due to activities requiring awkward and static postures, such as using child-sized furniture, sitting on the floor, or bending at the waist [25]. According to kindergarten teachers' own appraisals, a bent torso affects the voice most negatively [26].

Even short rest periods in the middle of voice loading tasks help the vocal organs to recover from loading changes [27]. Regular pauses also relieve neck and upper-limb pains if a worker has to look at the screen a lot [28]. Breaks as short as three minutes after every 20 minutes of work have been shown to relieve muscle tension in the region of the neck and shoulders [29]. 
On the basis of earlier studies and clinical experience, it can be assumed that ergonomically undesirable working postures may be deleterious to teachers' vocal well-being in the long term even if their postures are not as static as those of people in certain other occupations. Thus the aim of this research was to explore what kinds of ergonomically undesirable working postures teachers adopted during teaching and if these were associated with the occurrence of voice symptoms and acoustic features of the voice. We also ascertained if the number of working postures adopted had an impact on the voice.

\section{Materials and methods}

\section{Participants and their working environment}

Thirty-two female teachers (mean age 45 years, range $27-57$ years) and eight male teachers (mean age 39 years, range 31-45 years) from 14 different schools participated voluntarily in the study. Twenty-three teachers had been working for more than ten years, seven for between five and ten years and others for less than five years; one participant did not provide this information. Four teachers were smokers. One male teacher had a benign mass lesion in the vocal folds. The number of pupils in the classrooms varied from 10 to 28 (mean 20 pupils). The recruitment of the participants has been reported in more detail in the article of Rantala et al. [9].

The participants taught pupils aged between seven and 13 and used teacher-centred pedagogy. The mean number of pupils per classroom was 19 (range from 9 to 27). Eleven per cent of the pupils had a language other than Finnish as their first language, seven per cent had learning difficulties but no medical diagnosis, five per cent had some kind of speech-language impairment and two per cent 
had attention deficiency disorder. The sizes of the participants' classrooms were similar: the rooms were on average 8.4 metres long (SD 1.0 m), 7.5 metres wide (SD $0.9 \mathrm{~m}$ ) and 3.2 metres high (SD $0.24 \mathrm{~m})$.

The mean of background noise level $\left(\mathrm{L}_{\mathrm{Aeq} 1 \mathrm{~min}}\right)$ in the classrooms caused by appliances attached to the buildings was $35 \mathrm{~dB}$ (SD $5.6 \mathrm{~dB}$ ), which slightly exceeds the limits in the Finnish standards. Activity sound levels ( $\mathrm{L}_{\text {Aeq2-4 hours) }}$ ) were also high for speech communication (mean $69 \mathrm{~dB}, \mathrm{SD} 6.2$ $\mathrm{dB})$. Nor did the acoustic indices fulfill the recommendations in the most of the classrooms: reverberation time was satisfactory in $35 \%$ of the classrooms and the index for speech clarity (speech transmission index) in only one class. Information on classrooms is presented in more detail in an article by Sala and Rantala [30].

\section{Working postures}

Participants' working postures and related issues after a working day were assessed in their classrooms without the pupils. The evaluation was made at the same time as the whole voice ergonomic risk assessment with the VEAW. Altogether the assessment took about 40-60 minutes, of which the evaluation of the postures took 10-20 minutes.

The assessment (Table 1) comprised 11 items: a general evaluation of working postures (item 1), eight specific assessments from five different parts of the body (items 2-9), one assessment of the effect of furniture (item 10) and a question about opportunities to recover from loading (11). Items 1, 10 and 11 were elicited directly from the participants. A researcher (speech therapist) trained in the use of the assessment requested a participant to go to all the typical working sites used while teaching and demonstrate how the most characteristic tasks were performed. To help the researcher 
in making evaluations, the assessment form included written explanations and photos of desirable and undesirable postures (Figure 1 for unergonomic postures). When needed, participants were asked about their working postures such as 'Do you talk with your pupils when you use your blackboard/overhead projector? Please show how you do that? Is this posture typical for you?' If a posture was ergonomically desirable, the finding was scored zero $(0=$ no risk to the voice $)$ otherwise it was scored one ( $1=$ likely to cause a voice disorder). Thus, the maximum risk index was 13 points.

To calculate the inter-rater reliability of the posture assessments, three researchers watched videos where10 people showed their most typical speaking postures while working. To assess intra-rater reliability, two researchers repeated the assessment after one month. According to the analysis, the inter-rater (Cronbach's $\alpha$ was 0.8) and intra-rater coefficients (Spearman's rank order correlation coefficients 0.86 and 0.9 ) expressed that the assessments were sufficiently reliable.

\section{TABLE 1 ABOUT HERE}

The research was conducted with the approval of the relevant municipal education authorities. According to the legal advisor of the study organization, the study setting did not require ethical approval. The participants were anonymized with code numbers.

\section{Voice symptoms}

After the voice ergonomic assessment the participants were asked to complete two questionnaires about their voice symptoms . The first was the Finnish version (31) of the Voice Handicap Index (VHI). (32) The VHI is a questionnaire with three domains each comprising ten items: physical (VHI-P), functional (VHI-F) and emotional (VHI-E). The responses were scored on a five-point 
scale $(0=$ never, 1 = almost never, $2=$ sometimes, $3=$ almost always, and $4=$ always; 120 -point total). In the second questionnaire, the occurrence of seven voice symptoms was elicited. The voice symptoms were (1) voice tires easily, (2) hoarseness, (3) voice breaks, (4) aphonia lasting at least a couple of minutes during speaking, (5) difficulty in audibility due to voice problems, (6) throat clearing and (7) sore throat or globus in the throat. The participants responded on a five-point scale ( 4 = symptoms occur daily or almost daily; 3 = weekly or almost weekly; 2 = monthly or almost monthly; 1 = more seldom; and $0=$ no symptoms during the last 12 months). This questionnaire has been shown to effectively reveal voice disorders (33) and has also been used in several voice studies $[33-35]$.

\section{Voice samples and variables measured}

Two different voice samples were recorded: a one-minute long text reading of 102 words from a book 'People from Hemsö' by August Strindberg (in Finnish) and speech during lessons of one working day. The text is easy to read and commonly used in Finnish voice studies. The reading was recorded 30-60 minutes before work (morning sample) and 5-15 minutes after it (afternoon sample) in a quiet, unoccupied room at each school. The recordings were made with a digital $\mathrm{H} 2$ recorder (Zoom Corporation, Tokyo, Japan) and a headset microphone (C555 L, AKG, Vienna, Austria) at a distance of three centimetres from the corner of the mouth. The calibration for the measurements of voice SPL was made using a sound generator (BOSS TU-120, Roland Corporation, Los Angeles, CA) and a sound level meter (Brüel \& Kjær 2206). One female participant did not provide the afternoon voice samples.

Speech during lessons was recorded with a portable accelerometer (Ambulatory Phonation Monitor, APM, 3200 model 1.04, Kay-Pentax, Lincoln Park, NJ). The participants recorded one whole 
working day but only the recordings from the first and last lessons were included in the analysis of the present study.

Fundamental frequency $\left(\mathrm{F}_{0}\right)$ and sound pressure level $(\mathrm{SPL})$ were analysed from the text readings and speech during lessons. $\mathrm{F}_{0}$ and SPL from the two voice samples were measured as voice use measured outside classroom work seemed to better typify a teacher's habitual voice use, while speech during lessons revealed direct vocal reactions to the environment and vocal load [36]. The changes in $\mathrm{F}_{0}$ and SPL during work were calculated (difference between the values of the parameters measured from the first and the last lessons). $F_{0}$ of the morning and afternoon samples were studied separately for females and males. Further, the tilt of the sound spectrum slope called the alpha ratio (relationship of voice energy levels between SPL of $50 \mathrm{~Hz}-1 \mathrm{kHz}$ and SPL of $1-5$ $\mathrm{kHz}$ ) was calculated from the reading sample. This ratio expresses voice quality on a continuum of hypo-to-hyperfunctional mode of voice production. The change in the alpha ratio during a working day was also studied. The acoustic analyses were conducted with Praat software for Windows (Version 5.3.79) [37].

\section{Statistical analysis}

To study the effects of individual working postures the participants were divided into groups: one group consisted of those not using any ergonomically undesirable postures and the other group of those using one or more ergonomically undesirable postures. A similar categorization was made to study the effects of different numbers of postures. Wilcoxon signed-ranks test (independent samples) was used for the analyses. The group comparisons were computed separately for females' and males' $\mathrm{F}_{0} \mathrm{~S}$. A significance level of .05 was adopted because this study was essentially exploratory in nature. Too strict criteria might have led to missed findings. Effect size for the group 
differences was calculated with Cohen's d [38]. Interpretation of the values was as follows: $0.2=$ small, $0.5=$ medium and $0.8=$ large effect. The analyses were carried out with PASW Statistics 23.0 software for Windows operating system (SPSS, Inc., Chicago, IL).

\section{Results}

\section{Working postures during teaching while speaking}

Most of the participants $(90 \%, \mathrm{n}=36)$ reported that their working postures felt good. Everyone was also able to rest during the working day. However, according to the researcher's observations many participants used speaking postures which were likely to predispose them to a voice disorder (Figure 2). The most typical unergonomic posture observed was that the head was out of its neutral position: $60 \%(n=24)$ of the participants turned, thrust or tilted their heads or used an undesirable head posture because of varifocal or reading glasses. The head turned to the side was the most common of these postures, while the least typical $(7.5 \%, n=3)$ head posture was that caused by wearing glasses. Other frequently used unergonomic working postures were hunched upper back, raised shoulders and twisted torso. Most of the participants $(75 \%, \mathrm{n}=30)$ were able to adjust the tables and chairs in their classrooms.

\section{FIGURE 2 ABOUT HERE}

The participants mostly used $3-5$ unergonomic working postures while speaking $(40 \%, \mathrm{n}=16)$. Thirteen teachers (30\%) used one or two unergonomic postures and seven (18\%) used 6-8 poor postures. Of the participants, $12 \%(n=5)$ did not use any ergonomically undesirable posture while speaking in the classroom. 


\section{Voice symptoms and acoustic features of the voice}

The mean of the total scores of the VHI was 18 (SD 13.5). On the subscales, the mean of the physical domain (VHI-P) was highest at 8.6 (SD 5.9). The means for the other subscales were 5.4 (SD 4.46) for the VHI-F and 4.0 (SD 4.36) for the VHI-E. The most typical individual voice symptom for the participants was 'voice tires easily' (Table 2).

\section{TABLE 2 ABOUT HERE}

The SPL means were $72 \mathrm{~dB}(\mathrm{SD} 5.0 \mathrm{~dB}$ ) for the morning and $73 \mathrm{~dB}$ (SD $4.1 \mathrm{~dB}$ ) for the afternoon voice samples (text reading). The $\mathrm{F}_{0}$ means were $182 \mathrm{~Hz}(\mathrm{SD} 15.7 \mathrm{~Hz}$ ) for the morning and $185 \mathrm{~Hz}$ (SD 17.2 Hz) for the afternoon samples among the female participants and $97 \mathrm{~Hz}(\mathrm{SD} 11.6 \mathrm{~Hz})$ and $102 \mathrm{~Hz}$ (SD 14.9 Hz) among the males. The means of alpha ratios were -15.7 (SD 2.56) for the morning and -15.2 (SD 2.06) for the afternoon samples.

For speaking in the classroom (all lessons) the mean SPL was $75 \mathrm{~dB}$ (SD $5.5 \mathrm{~dB}$ ) and this changed only slightly between the first and last lessons (mean for the change $0.3 \mathrm{~dB}, \mathrm{SD} 6.6 \mathrm{~dB}$ ). The $\mathrm{F}_{0}$ mean for all the lessons was $225 \mathrm{~Hz}(\mathrm{SD} 22.3 \mathrm{~Hz}$ ) among the female participants and $130 \mathrm{~Hz}$ (SD 15.0 Hz) among the males. $\mathrm{F}_{0}$ changed during lessons by $6.5 \mathrm{~Hz}(\mathrm{SD} 18.7 \mathrm{~Hz})$ among all participants.

Effects of working postures: comparisons between teachers who used or did not use ergonomically undesirable postures 
Only a small number of the participants did not use any unergonomic postures $(n=5)$. Their voices did not tire as easily (mean score 2.4, SD 1.14) and they did not have so many difficulties in audibility (mean score 1.2, SD 0.45) as did the teachers speaking while using unergonomic postures (mean score 3.68 and SD 1.27 for the voice tiring and 2.5 and 1.18 respectively for difficulties with audibility). In addition, the alpha ratios of the voices decreased (became more hypofunctional) in the participants using ergonomic postures $(-1.6 \mathrm{~dB}, \mathrm{SD} 1.69 \mathrm{~dB})$ but increased somewhat (became more hyperfunctional) in those adopting harmful postures $(0.7 \mathrm{~dB}, \mathrm{SD} 1.48 \mathrm{~dB})$. Because the group size was small for the teachers using ergonomic speaking postures, the results are only indicative.

The results showed that those participants who turned their heads, twisted their torsos and raised their arms while speaking were more likely to experience specific voice symptoms than were those who did not use these postures (Table 3). The effect sizes for the differences between the two groups were medium except that the difference for aphonia was small (-0.027). In addition, a small group $(n=5)$ were in the habit of talking with the head tilted. They scored higher on the physical subscale of the VHI (mean 13.4 scores, SD 5.72) than did those who did not use that posture (mean 7.9 scores, SD 5.32).

\section{TABLE 3 ABOUT HERE}

If the participants thrust their heads forward while talking in the classroom their $\mathrm{F}_{0}$ decreased on average $4 \mathrm{~Hz}$ and SPL decreased $4 \mathrm{~dB}$ (measured during lessons; Table 4). In those teachers who did not adopt this head posture the values of the variables increased ( $\mathrm{F}_{0}$ mean: $\left.9 \mathrm{~Hz}\right)$ or remained almost the same (SPL mean: $1 \mathrm{~dB}$ ). Post hoc analysis showed that the $\mathrm{F}_{0}$ change was significant only for the teachers adopting an ergonomic head posture $(p=.004)$ while the SPL change was significant for the teachers adopting an unergonomic head posture $(\mathrm{p}=.021)$. The alpha ratio 
increased on average $0.83-1 \mathrm{~dB}$ (voice became more hyperfunctional) in those teachers who hunched their upper backs and turned their heads but decreased $0.2-0.5 \mathrm{~dB}$ in those did not adopt these postures while speaking. SPL was $3 \mathrm{~dB}$ higher in those participants who talked with hunched upper back. The effect sizes of the head positions on the acoustic variables (ES -0.89 for alpha ratio change and 0.84 for SPL change) were large.

A small group $(n=3)$ using unergonomic head posture due to wearing spectacles or varifocal glasses had a tendency to lower their $\mathrm{F}_{0}$ (decreased $18 \mathrm{~Hz}, \mathrm{SD} 16.5$ ) and SPL (decreased $7 \mathrm{~dB}, \mathrm{SD} 5.6$ ) measured during lessons, whereas these variables increased in the teachers $(n=37)$ who did not use this posture (rise for $\mathrm{F}_{0} 8 \mathrm{~Hz}$, SD 17.5 and SPL $0.4 \mathrm{~dB}$, SD 6.2). Because of a low sample size, no significance level was calculated.

\section{TABLE 4 ABOUT HERE}

\section{Effects of the number of ergonomically undesirable working postures}

The participants who used two or more ergonomically undesirable working postures while speaking suffered more often from physical voice symptoms (measured with the VHI) than did those who used only one or none these postures (Table 5). Using four or more unergonomic postures was particularly associated with the symptom of voice break: the participants with this number of postures experienced the symptom on average weekly, while those with less than four undesirable postures suffered the symptom monthly or more seldom. The effect size was also large $(-0.90)$. The number of postures also affected voice production (Table 6). The greatest effect size for the number of postures $(-1.1)$ was found in the morning voice samples if the teachers used four or more unergonomic working postures. The SPL of these teachers was on average $5 \mathrm{~dB}$ louder than those 
teachers with fewer than four unergonomic postures. The effect size was also large for change in $\mathrm{F}_{0}$ during lessons (1.05). The value of this variable increased much more $(18 \mathrm{~Hz})$ in those teachers who used one or no unergonomic posture than in those using more undesirable postures (increase only 2 $\mathrm{Hz}$ ). According to post hoc analysis, the $\mathrm{F}_{0}$ change was significant $(\mathrm{p}=.003)$ for those teachers who used only one unergonomic posture. The SPL also changed differently in those groups but the change was not statistically significant in either group.

\section{TABLE 5 AND 6 ABOUT HERE}

\section{Discussion}

We introduced a tool for assessing speaking postures used during teaching. In clinical work, improving postures is a relevant part of voice therapy and education. However, a tool for assessing unergonomic postures in voice patients has been lacking and scientific evidence on the effects of speaking postures has also been sparse. Although the results of the present study raised rather more questions than providing specific answers, trends regarding speaking postures and their impacts on voice could be discerned.

According to the results, teachers typically used from three to five unergonomic speaking postures during teaching and about one fifth of the teachers used as many as six or more poor postures. The most common ergonomically undesirable postures were turned head and hunched upper back. The results also revealed that unergonomic postures were associated with more frequent occurrence of self-reported voice symptoms and potentially harmful vocal adaptations. The teachers' own evaluations of their postures were that they generally felt good. This finding suggests that teachers may mostly be unaware of the voice loading caused by the postures they use. Only five participants 
$(13 \%)$ did not use any risky speaking postures. These teachers' voices tended to endure better and their voice quality did not become hyperfunctional as happened to the voices of those using unergonomic postures.

The good news of the present study was that all the teachers had opportunities to rest in the course of their work, which is known to support vocal health [27]. Because every participant could take breaks, the connection between rest and voice could not be studied here. Most of the teachers were also able to adjust tables and chairs to suit their needs and this may explain why the effect of the variable could be found on neither the voice symptoms nor voice use.

The postures were not associated with the voice variables in the same way; some were connected to the occurrence of voice symptoms while others were connected to voice production. The postures causing voice symptoms were turned torso and head and raised shoulders and arms, whereas acoustic features of the voice were affected by forward thrust head and hunched upper back. Only one posture - the turned head - affected both voice symptoms and acoustic features. Because voice symptoms mostly indicate more serious voice problems (expressing possible alterations in vocal organs) than changes in acoustic features of voice (not necessarily changes in vocal organs but may express changed vocal behavior due to loading), the results suggest that that turned postures and raised upper limbs may load more vocal organs more severely than do other speaking postures.

One reason why twisted postures load the voice organs may be increased tension in the muscles causing unequal distribution of biomechanical loading on the spine $[1,2,39]$. This stress has also been shown to lead to back pain [39]. Asymmetrical postures also bring unequal stretching forces to bear on the components of the larynx and hence disturb voice use and may cause voice symptoms in 
the course of time. The voice symptoms found in the present study - particularly voice breaks may be one manifestation of this.

Raised shoulders and arms were another posture group increasing the occurrence of voice symptoms (higher scores in VHI-P and aphonia respectively). The harmful effect of the postures is corroborated in the work of Koojiman et al. [12], showing that pain in the shoulders raises the occurrence of voice symptoms. The present study showed specifically that raised arms were associated with a serious voice symptom, that is, aphonia. Although the connection was only tenuous, it nevertheless suggests that this posture may cause a risk for a voice disorder.

The hunched upper back posture in particular may affect voice use by restricting the breathing movements. This posture inhibits the lateral expansion of the ribs and the descent of the diaphragm by shortening the pectoral muscles and adaptively the abdominal muscles [2]. Weak activity in the diaphragm may lead a speaker to talk at the end of normal expiration thereby increasing laryngeal muscle tension [40]. The finding that voice quality became more hyperfunctional during work among those teachers with hunched upper back may reflect this phenomenon. It moreover seems that the same teachers also used higher SPL before work. Could it be so that hyperfunctional voice use had irritated the teachers' vocal organs causing poor voice quality and/or increased phonation threshold pressure the next morning and this was why they had to increase their voice loudness? Earlier research supports this explanation: for instance, teachers whose classrooms have many voice ergonomic risk factors use higher SPLs, particularly before work, than do teachers with better voice ergonomic environments [41, 42].

The forward thrust head affected $\mathrm{F}_{0}$. If the teachers used this head posture, their $\mathrm{F}_{0}$ decreased somewhat $(-4 \mathrm{~Hz})$ during lessons but if they did not use it their $\mathrm{F}_{0}$ rose $(9 \mathrm{~Hz})$. According to Rubin 
et al. $[3,18]$ the forward head posture elevates the larynx by shortening the muscles attached to the hyoid bone and the processes of the temporal lobe of the skull that, in turn, leads to the shortening of other suprahyoid musculature, thereby affecting pitch. However, it is not clear how the raised larynx affects $\mathrm{F}_{0}$ because the evidence of a relationship between these two factors is inconclusive. A positive correlation between the height of the larynx and $\mathrm{F}_{0}$ was found in studies where vocally healthy participants produced sustained vowels $[20,21,43]$. In turn, clinical studies have shown that although patients with voice disorders held their larynges high, they did not, however, use high $\mathrm{F}_{0}[44]$ or their $\mathrm{F}_{0}$ did not systematically decrease although their larynges were lowered during the treatment of manual laryngeal reposturing and circumlaryngeal massage [45]. It, therefore, seems that imbalance in the neck muscles interferes with the natural physiological co-operation between the vertical laryngeal position and $\mathrm{F}_{0}$. This explanation gains support from Rubin et al. [3, 18], who have contemplated musculoskeletal patterns in voice patients, and suggest that the high held larynx may restrict the use of higher frequencies because it resists the upward and forward movement of the hyoid bone and thyroid cartilage. They also conjectured that the raised larynx may cause chronic contraction of the cricothyroid muscle which, by inhibiting forward movement of the thyroid cartilage, limits voice pitch variation. Note that we did not palpate our participants' larynges and can therefore not state for sure if their larynges were elevated.

A parallel but greater difference in $\mathrm{F}_{0}$ change was found between the groups of teachers with different numbers of ergonomically undesirable postures (group $\leq 1$ unergonomic posture vs. group $\geq 2$ unergonomic postures). Thus, it seems that the rise of $F_{0}$ may rather represent the capacity of a muscle to change and hence a health physiological reaction to daily loading caused by speaking than it would unambiguously indicate a pathological alteration. Rubin et al. $[3,18]$ regarding the shortening tendency in the musculature caused by unergonomic postures suggest that this may also explain this phenomenon. Furthermore, results from earlier studies also support the conclusion that 
the $\mathrm{F}_{0}$ increase has to do with a normal loading reaction [46-48]. To better understand loading effects, more research is needed to ascertain the different reaction patterns of people using unergonomic speaking postures.

The forward head thrust was associated with another acoustic parameter in addition to $\mathrm{F}_{0}$, namely SPL. This decreased $(-4 \mathrm{~dB})$ during lessons in the teachers speaking with the unergonomic head posture while it increased slightly $(1 \mathrm{~dB})$ in those who did not. Decreased SPL may derive from difficulties in vocal projection because of unfavourable changes in the vocal tract: the lifted chin bends the pharyngeal region in the mouth, which effectively narrows the resonance and amplifying chamber at the base of the tongue $[18,19]$. Moreover, elevated position of the larynx due to muscle tension may also have decreased voice loudness [18]. In the other hand, decreasing voice levels may also indicate the teachers' attempt to protect their voice organs from the consequences of loading caused by the unergonomic head posture. Because the number of teachers in the group with extended heads was small $(n=9)$, the result remains tentative.

The results of the present study do not permit us to propose a critical number of ergonomically undesirable postures having an effect on voice. Although the number of unergonomic postures was connected to both voice symptoms and voice production, there was no specific level after which the effect of unergonomic postures became consistent. In spite of this, a tendency did emerge: the effect size of the posture rate was greatest when the teachers used four or more unergonomic working postures. The number of speaking postures was associated with voice SPL in particular. The more unergonomic postures the teachers used, the higher were their SPLs before and after work (measured from text reading). This suggests that speakers react to loading changes by increasing voice SPL in the long term. 
Although the differences between the values of the acoustic variables in the present study were not great, the effect size of several differences was large, indicating that even small changes in voice features may constitute a risk for a voice disorder if a speaker uses the same speaking postures for years. The finding that the associations were not detected simultaneously between a specific posture and voice symptoms and production is difficult to explain. One reason may be that the most of the teachers used several unergonomic speaking postures. Another reason may be the nature of the muscle loading, the magnitude of which was low but long-lasting. This kind of loading leads to a long latency time for a disorder [7, 49]. A third reason may result from individual reaction patterns. For instance, workers who suffer from work-related muscle pain have been found to use muscles differently from those who have no pain [50]. Further, the sensitivity of the structures for loading differs across individuals; tense laryngeal muscles may cause dysphonia in one speaker but not in another [51]. Lastly, selecting other acoustic parameters for scrutiny might have resulted in a more consistent picture of the associations between postures and voice variables than we found now.

\section{Methodical considerations}

In spite of many computations the significance level of .05 was accepted which caused a risk of type I error. Hence, this study rather screened postures associated with voice symptoms and voice use than presented robust evidence of the effects of the postures on the voice. To improve the analysis we also computed the effect size to establish the clinical relevance of the findings. Obviously, many factors other than postures affected the participants' voices. Further, the validity of the results is impaired due to some groups being small and to differences in the numbers of participants in the groups. To improve the reliability of the results, a control group without any unergonomic speaking postures would have been needed. Unfortunately this may often be 
impossible if one wants to study occupational voice users such as teachers, whose working postures are not static.

A reliable evaluation of working postures during speaking is not easy. This has also challenged researchers in general occupational ergonomics and only few scientific papers on working postures and their effects have been presented [7]. Although in the present study the assessment was made outside classroom work, the concreteness of the instructions may have served as a cue for the participants to monitor their postures (cued recall) [52]. The teachers were requested to go to their typical working spots and show how they used their hands, moved their bodies, looked in different directions and so on. This was, indeed, what our participants did. The usefulness of concrete cues when studying postures gets support indirectly from two internet surveys using data collected by questionnaire. The studies revealed no associations between speaking postures and voice symptoms $[15,26]$.

Exposure factors for loading are intensity, duration and frequency of postures [49], and it would have been relevant to measure the last two of these. Although this was not done the factors were implicitly included in the procedure by asking the participants to demonstrate their typical postures. Furthermore, because the participants used teacher-centred pedagogy, their postures were not very diverse: they used blackboards, audio-visual equipment and computers, gave instructions and helped pupils. Hence, it may be assumed that the most common postures were detected, most of them, at least.

Video recording could have been used to learn more about postures during speaking, but the disadvantage is that analysis is time-consuming and analytical methods are lacking. Moreover, video recording in a classroom may change a teacher's behaviour and requires permission from 
every pupil's parent or guardian; a single refusal would prevent it. A video recording lasting only one day might not give a comprehensive picture of the working postures because we do not know how much data is needed to determine a teacher's typical postures during lessons. This also calls for further research.

\section{Conclusions}

The results of this study showed that teachers' unergonomic postures during teaching were associated with voice production although teaching postures are not as static as postures in certain other occupations, and the teachers themselves evaluated their postures to be good. This suggests that even low levels of prolonged muscle contraction may predispose to disorders, as demonstrated in rehabilitative medicine [7]. Furthermore, the results also imply that evaluating postures and offering workers advice on correcting them should be an essential part of voice ergonomic assessment. In order to take care of the voice, a speaker ought to understand the value of a good postural alignment while speaking, learn to pay attention to it and find means to use ergonomically optimal working postures.

\section{Acknowledgements}

This study was funded by The Finnish Work Environment Fund. Mrs. Virginia Mattila, MA, is thanked for language correction of the manuscript.

\section{Conflicts of Interest}

Authors have no conflicts of interest.

1 Schneider CM, Dennehy CA, Saxon KG. Exercise physiology principles applied to vocal performance: the improvement of postural alignment. J Voice 1997;11:332-337. 
2 Wilson Arboleda BM, Frederick AL: Considerations for maintenance of postural alignment for voice production. J Voice 2008;22:90-99.

3 Rubin JS, Mathieson L, Blake E: Care of the professional voice: Posture and voice. J Sing 2004;60:271-275.

4 Lagier A, Vaugoyeau M, Ghio A, Legou T, Giovanni A, Assaiante C: Coordination between posture and phonation in vocal effort behavior. Folia Phoniatr Logop 2010;62195-202.

5 Behrman A: Common practices of voice therapists in the evaluation of patients. J Voice 2005;19:454-469.

6 Bruno E, De Padova A, Napolitano B, Marroni P, Batelli R, Ottaviani F, Alessandrini M: Voice disorders and posturography: Variables to define the success of rehabilitative treatment. J Voice 2009;23:71-75.

7 Vieira ER, Kumar S: Working postures: a literature review. J Occup Rehabil 2004;14:143-159.

8 Sala E, Hellgren U, Ketola R, Laine L, Olkinuora P, Rantala L, et al. Voice Ergonomic Assessment in Work Environment - Handbook and Checklist (in Finnish and Swedish). Helsinki, The Finnish Institute of Occupational Health, 2009.

9 Rantala LM, Hakala SJ, Holmqvist S, Sala E: Connections between voice ergonomic risk factors and voice symptoms, voice handicap, and respiratory tract diseases. J Voice 2012;26:819.e13-819.e20.

10 Rantala LM, Hakala S, Holmqvist S, Sala E. Connections between voice ergonomic risk factors in classrooms and teachers' voice production. Folia Phoniatr Logop 2013;64:278-282.

11 Erick PN, Smith DR: A systematic review of musculoskeletal disorders among school teachers. BMC Musculoskelet disord 2011;12:260.

12 Kooijman PGC, de Jong FICRS, Thomas G, Huinck W, Donders R, Graamans K, et al: Risk factors for voice problems in teachers. Folia Phoniatr Logop 2006;58:159-174. 
13 Chiu TT, Lam PK: The prevalence of and risk factors for neck pain and upper limb pain among secondary school teachers in Hong Kong. J Occup Rehabil 2007;17:19-32.

14 Korkmaz NC, Cavlak U, Telci EA: Musculoskeletal pain, associated risk factors and coping strategies in school teachers. Sci Res Essays 2011;6:649-657.

15 Ilomäki I, Leppänen K, Kleemola LM, Tyrmi J, Laukkanen AM, Vilkman E. Relationships between self-evaluations of voice and working conditions, background factors, and phoniatric findings in female teachers. Logoped Phoniatr Vocol 2009;34:20-31.

16 Kooijman PGC, de Jong FICRS, Oudes MJ, Huinck W, van Acht H, Graamans K: Muscular tension and body posture in relation to voice handicap and voice quality in teachers with persistent voice complaints. Folia Phoniatr Logop 2005;57:134-147.

17 Seikel JA, Drumright DG, King DW: Anatomy \& Physiology for Speech, Language, and Hearing, ed. $5^{\text {th }}$. Clifton Park NY, Cengage Learning, 2014.

18 Rubin JS, Blake E, Mathieson L: Musculoskeletal patterns in patients with voice disorders. J Voice $2007 ; 21: 477-484$.

19 Heman-Ackah YD: Care of the professional voice: Physiology of voiceproduction: Consideration for the vocal performer. J Sing 2005;62:173-176.

20 Honda K, Masaki S, Shimada Y: Observation of laryngeal control for voicing and pitch change by magnetic resonance imaging technique. $6^{\text {th }}$ International Conference on Spoken Language Processing, 2000. https://pdfs.semanticscholar.org/7627/6dbb88d203bf57f78e8c7c1508d80bd4f1b6.pdf

21 Honda K, Hirai H, Masaki S, Shimada Y: Role of vertical larynx movement and cervical lordosis in F0 control. Lang Speech 1999;42:401-411.

22 Franco D, Martins F, Andrea M., Fragoso I, Carrão L, Teles J: Is the sagittal postural alignment different in normal and dysphonic adult speakers? J Voice 2014;28:523-e1. 
23 O’sullivan PB, Grahamslaw KM, Kendell M, Lapenskie SC, Möller NE, Richards V: The effect of different standing and sitting postures on trunk muscle activity in a pain-free population. Spine 2002;27:1238-1244.

24 Bonney RA, Corlett EN: Head posture and loading of the cervical spine. Appl Ergon 2002;33:415-417.

25 Grant KA, Habes DJ, Tepper AL: Work activities and musculoskeletal complaints among preschool workers. Appl Ergon 1995;26:405-410.

26 Kankare E, Geneid A, Laukkanen A, Vilkman E. Subjective evaluation of voice and working conditions and phoniatric examination in kindergarten teachers. Folia Phoniatr Logop $2011 ; 64: 12-19$.

27 Vintturi J, Alku P, Lauri ER, Sala E, Sihvo M, Vilkman, E: The effects of post-loading rest on acoustic parameters with special reference to gender and ergonomic factors. Folia Phoniatr Logop 2001;53:338-350.

28 van den Heuvel SG, de Looze MP, Hildebrandt VH, Thé KH: Effects of software programs stimulating regular breaks and exercises on work-related neck and upper-limb disorders. Scand J Work, Environ Health 2003;29:106-116.

29 Nakphet N, Chaikumarn M, Janwantanakul P: Effect of different types of rest-break interventions on neck and shoulder muscle activity, perceived discomfort and productivity in symptomatic VDU operators: a randomized controlled trial. Int J Occup Saf Ergon 2014;20:339-353.

30 Sala E, Rantala L: Acoustics and activity noise in school classrooms in Finland. Appl Acoust 2016;114:252-259.

31 Alaluusua S, Johansson M: Psycho-social handicap of voice disorder and its rehabilitation: a pilot study of Finnish version of Voice Handicap Index (in Finnish). Master thesis. Helsinki, Institute of Behavioral Sciences, University of Helsinki, 2003. 
32 Jacobson B, Johnson A, Grywalski C, Silbergleit A, Jacobson B, Benninger M, Newman CW: The voice handicap index (VHI): development and validation. Am J Speech Lang Pathol 1997;6:66-70.

33 Simberg S, Sala E, Laine A, Rönnemaa AM: A fast and easy screening method for voice disorders among teacher students. Log Phon Vocol 2001;26:10-16.

34 Sala E, Laine A, Simberg S, Pentti J, Suonpää T: The prevalence of voice disorders among day care center teachers compared with nurses: a questionnaire and clinical study. J Voice 2001;15: $413-423$.

35 Ohlsson A, Andersson EM, Södersten M, Simberg S, Barregård L: Prevalence of voice symptoms and risk factors in teacher students. J Voice 2012;26:629-634.

36 Rantala L, Lindholm P, Vilkman E: F0 change due to voice loading under laboratory and field conditions. A pilot study. Log Phon Vocol 1998;23:164-168.

37 Boersma P, Weenik, D: Praat: Doing phonetics by computer (5.3.56). http://www.fon.hum.uva.nl/praat/

38 Cohen J. Statistical Power Analysis for Behavioral Sciences, ed. 2. Hillside, NJ, Erlbaum, 1988. 39 Pope MH, Goh KL, Magnusson ML: Spine ergonomics. Annu Rev Biomed Eng 2002;4:49-68 40 Stemple JC, Glaze LE, Klaben BG: Clinical voice pathology: theory and management, ed. $3^{\text {th }}$. San Diego (Calif.), Singular, 2000.

41 Rantala LM, Hakala S, Holmqvist S, Sala E: Associations between voice ergonomic risk factors and acoustic features of the voice. Log Phon Vocol 2015;40:99-105.

42 Sala E, Holmqvist S, Rantala LM, Hakala S, Jonsdottir VI: Activity noise in comprehensive school classrooms in Finland. Inter-Noise Conference Proceedings 2013;247:1375-1382.

43 Shipp T: Vertical laryngeal position during continuous and discrete vocal frequency change. J Speech Hear Res 1975;18:707-718. 
44 Lowell SY, Kelley RT, Colton RH, Smith PB, Portnoy JE: Position of the hyoid and larynx in people with muscle tension dysphonia. Laryngoscope 2012;122:370-377.

45 Roy N, Hendarto H: Revisiting the pitch controversy: Changes in speaking fundamental frequency (SFF) after management of functional dysphonia. J Voice 2005;19:582-591.

46 Ben-David BM, Icht M: Voice changes in real speaking situations during a day, with and without vocal loading: assessing call center operators. J Voice 2016; 30:247-e1.

47 Remacle A, Finck C, Roche A, Morsomme D: Vocal impact of a prolonged reading task at two intensity levels: Objective measurements and subjective self-ratings. J Voice 2012;26: e177-e186.

48 Rantala L, Vilkman E, Bloigu R: Voice changes during work: subjective complaints and objective measurements for female primary and secondary schoolteachers. J Voice 2002;16:344-355.

49 Hagberg M: Epidemiology of neck and upper limb disorders and work place factors; in Violante F, Kilbom A, Armstrong TJ (eds.): Occupational ergonomics: work related musculoskeletal disorders of the upper limb and back. London, CRC Press, 2000, pp 22-28.

50 Szeto GPY, Straker LM, O’Sullivan PB: A comparison of symptomatic and asymptomatic office workers performing monotonous keyboard work -1 : Neck and shoulder muscle recruitment patterns. Man Ther 2005;10:270-280.

51 Van Houtte E, Claeys S, Wuyts F, Van Lierde K:Voice disorders in teachers: occupational risk factors and psycho-emotional factors. Log Phon Vocol 2012;37:107-116.

52 Schacter DL, Addis DR: The cognitive neuroscience of constructive memory: Remembering the past and imagining the future. Philos Trans R Soc Lond B Biol Sci 2007; 362:773-786. 


\section{TABLES}

Table 1. Questions on parts of the body and related matters in the assessment of wocorking postures.

\begin{tabular}{|c|c|c|}
\hline $\begin{array}{l}\text { Parts of the body or factors } \\
\text { affecting postures }\end{array}$ & Targets for observation or elicitation & $\begin{array}{l}\text { Supplementary } \\
\text { questions }\end{array}$ \\
\hline $\begin{array}{ll}1 & \text { Overview of working } \\
\text { postures (question to a } \\
\text { worker) }\end{array}$ & $\begin{array}{l}\text { Does a worker say that a working } \\
\text { posture feels bad? }\end{array}$ & \\
\hline Torso & $\begin{array}{l}\text { Does a worker twist the torso to the side } \\
\text { while speaking? }\end{array}$ & $\begin{array}{l}\text { E.g. when using a smart } \\
\text { board }\end{array}$ \\
\hline Head & Is a worker's head turned & $\begin{array}{l}\text { E.g. while speaking to } \\
\text { people at the side or } \\
\text { behind }\end{array}$ \\
\hline 4 & $\begin{array}{l}\text { Does a worker thrust the head or chin } \\
\text { upwards, forwards or backwards? }\end{array}$ & $\begin{array}{l}\text { E.g. while playing a } \\
\text { piano and singing }\end{array}$ \\
\hline 5 & $\begin{array}{l}\text { Does a worker tilt the head toward the } \\
\text { shoulder while speaking }\end{array}$ & $\begin{array}{l}\text { E.g. when using a } \\
\text { telephone }\end{array}$ \\
\hline 6 & $\begin{array}{l}\text { If a worker uses spectacles or varifocal } \\
\text { glasses, is the head or neck in a bad } \\
\text { posture? }\end{array}$ & $\begin{array}{l}\text { E.g. when trying to look } \\
\text { at a screen or books or } \\
\text { to look at pupils }\end{array}$ \\
\hline Upper back & $\begin{array}{l}\text { Is the worker's upper back hunched and } \\
\text { shoulders rounded? }\end{array}$ & $\begin{array}{l}\text { E.g. while working on a } \\
\text { computer }\end{array}$ \\
\hline Shoulders & $\begin{array}{l}\text { Are the worker's shoulders tense or } \\
\text { raised? }\end{array}$ & \\
\hline Arms & $\begin{array}{l}\text { Does a worker raise the arms while } \\
\text { holding things in the hands or lifting } \\
\text { heavy objects? }\end{array}$ & $\begin{array}{l}\text { E.g. while reading to } \\
\text { children }\end{array}$ \\
\hline $\begin{array}{ll}10 & \begin{array}{l}\text { Factors affecting } \\
\text { postures }\end{array}\end{array}$ & $\begin{array}{l}\text { Can chairs and tables be adjusted for a } \\
\text { worker in different speaking situations? }\end{array}$ & \\
\hline $\begin{array}{l}11 \text { Recovery from } \\
\text { loading }\end{array}$ & $\begin{array}{l}\text { Can a worker rest and move around } \\
\text { from time to time? }\end{array}$ & \\
\hline
\end{tabular}

Table 2. Occurrence of voice symptoms in participants (percentages in parentheses). $\mathrm{N}=39$

\begin{tabular}{llllll}
\hline $\begin{array}{l}\text { Voice } \\
\text { symptom }\end{array}$ & Daily & Weekly & Monthly & More seldom & $\begin{array}{l}\text { No } \\
\text { symptoms }\end{array}$ \\
\hline $\begin{array}{l}\text { Voice tires } \\
\text { easily }\end{array}$ & $12(31)$ & $9(23)$ & $8(21)$ & $7(18)$ & $3(8)$ \\
\hline $\begin{array}{l}\text { Voice gets } \\
\text { low }\end{array}$ & $8(21)$ & $6(15)$ & $11(28)$ & $11(28)$ & $3(8)$ \\
\hline Voice breaks & $3(8)$ & $2(5)$ & $7(18)$ & $18(46)$ & $9(23)$ \\
\hline Aphonia & $1(3)$ & 0 & $1(3)$ & $7(18)$ & $30(77)$ \\
\hline
\end{tabular}




\begin{tabular}{llllll}
\hline $\begin{array}{l}\text { Difficulty in } \\
\text { audibility due } \\
\text { to voice }\end{array}$ & $2(5)$ & $4(10)$ & $2(5)$ & $16(41)$ & $15(39)$ \\
\hline $\begin{array}{l}\text { Throat } \\
\text { clearing }\end{array}$ & $7(18)$ & $9(23)$ & $10(26)$ & $11(28)$ & $2(5)$ \\
\hline $\begin{array}{l}\text { Sore throat or } \\
\text { globus }\end{array}$ & $4(10)$ & $8(21)$ & $12(31)$ & $7(18)$ & $8(21)$ \\
\hline
\end{tabular}

Table 3. Differences between the occurrences of voice symptoms in teachers who used a specific unergonomic posture (unE group) and those who did not (E group). Group sizes (n) are given in the first column. Note only 5 participants did not use any unergonomic postures.

\begin{tabular}{|c|c|c|c|c|c|c|c|c|c|}
\hline \multirow[t]{2}{*}{$\begin{array}{l}\text { Posture and } \\
\mathrm{n} \text { for groups }\end{array}$} & & \multicolumn{2}{|c|}{ VHI-P } & \multicolumn{2}{|c|}{$\begin{array}{l}\text { Difficulty in } \\
\text { audibility due } \\
\text { to voice }\end{array}$} & \multicolumn{2}{|c|}{ Voice breaks $^{1}$} & \multicolumn{2}{|c|}{ Aphonia $^{1}$} \\
\hline & & $E$ & unE & $\mathrm{E}$ & unE & $E$ & unE & $\mathrm{E}$ & unE \\
\hline Head turned & Mean & 6.8 & 10.8 & 1.6 & 2.38 & & & & \\
\hline $\mathrm{E}=18 ;$ un $\mathrm{E}=21$ & SD & 4.92 & 6.35 & 0.85 & 1.28 & & & & \\
\hline $\mathrm{p}$ (Z-value) & & \multicolumn{2}{|c|}{$.031(-2.161)$} & \multicolumn{2}{|c|}{$.032(-2,14)$} & & & & \\
\hline ES & & \multicolumn{2}{|c|}{-0.74} & \multicolumn{2}{|c|}{-0.68} & & & & \\
\hline Body turned & Mean & & & & & 1.14 & 1.59 & & \\
\hline $\mathrm{E}=22 ;$ un $\mathrm{E}=17$ & SD & & & & & 0.47 & 1.0 & & \\
\hline $\mathrm{p}$ (Z-value) & & & & \multicolumn{6}{|c|}{$.025(-2.24)$} \\
\hline ES & & & & \multicolumn{6}{|c|}{-0.77} \\
\hline Shoulders raised & Mean & 6.8 & 10.8 & & & & & & \\
\hline$E=20-21 ;$ unE $=18-19$ & SD & 4.92 & 6.35 & & & & & & \\
\hline p (Z-value) & & \multicolumn{2}{|c|}{$.031(-2.161)$} & & & & & & \\
\hline ES & & \multicolumn{2}{|c|}{-0.70} & & & & & & \\
\hline Arms raised & Mean & & & & & & & 1.27 & 1.46 \\
\hline$E=26 ;$ un $E=13$ & SD & & & & & & & 0.87 & 0.52 \\
\hline $\mathrm{p}$ (Z-value) & & & & & & & & & $2.13)$ \\
\hline ES & & & & & & & & & \\
\hline
\end{tabular}

VHI-P = physical subscale of VHI, $\mathrm{SD}=$ standard deviation, $\mathrm{Z}=$ test statistic for Wilcoxon signedranks test, $p=$ probability value, $E S=$ effect size. $N=39$

${ }^{1}$ Range of scores for specific voice symptoms $0-4$ 
Table 4. Differences between voice variables in teachers who used a specific unergonomic posture (unE) and those who did not (E). Group sizes (n) are given in the first column. Note only 5 participants did not use any unergonomic postures.

\begin{tabular}{|c|c|c|c|c|c|c|c|c|c|}
\hline \multirow{3}{*}{$\begin{array}{l}\text { Posture and } n \text { for } \\
\text { groups } \mathrm{E} \text { and unE }\end{array}$} & & \multicolumn{4}{|c|}{ Before and after work } & \multicolumn{4}{|c|}{ During lessons } \\
\hline & & \multicolumn{2}{|c|}{$\begin{array}{c}\text { SPL } \\
\text { before }\end{array}$} & \multicolumn{2}{|c|}{$\begin{array}{l}\text { Alpha ratio } \\
\text { change }(\mathrm{dB})\end{array}$} & \multicolumn{2}{|c|}{$\begin{array}{c}\mathrm{F}_{0} \text { change } \\
(\mathrm{Hz})\end{array}$} & \multicolumn{2}{|c|}{$\begin{array}{l}\text { SPL change } \\
\text { (dB) }\end{array}$} \\
\hline & & $\mathrm{E}$ & unE & $\mathrm{E}$ & unE & $\mathrm{E}$ & unE & $\mathrm{E}$ & unE \\
\hline $\begin{array}{l}\text { Head turned } \\
E=17 ; \text { unE }=22\end{array}$ & $\begin{array}{l}\text { Mean } \\
\text { SD }\end{array}$ & & & $\begin{array}{l}-0.5 \\
(1.5)\end{array}$ & $1(1.5)$ & & & & \\
\hline $\begin{array}{l}\mathrm{p} \text { (Z-value) } \\
\mathrm{ES}\end{array}$ & & & & .01 & $\begin{array}{l}2.579) \\
89\end{array}$ & & & & \\
\hline $\begin{array}{l}\text { Head thrust } \\
\text { forward } \\
E=31 ; \text { unE }=9\end{array}$ & $\begin{array}{l}\text { Mean } \\
\text { SD }\end{array}$ & & & & & $\begin{array}{c}9 \\
(17.8 \\
)\end{array}$ & $\begin{array}{c}-4 \\
(18.5 \\
) \\
\end{array}$ & $\begin{array}{c}1 \\
(6,6 \\
) \\
\end{array}$ & $\begin{array}{c}-4 \\
(4.9) \\
\end{array}$ \\
\hline $\begin{array}{l}\mathrm{p}(\mathrm{Z} \text {-value }) \\
\text { ES }\end{array}$ & & & & & & $\begin{array}{r}.046( \\
-0 \\
\end{array}$ & $\begin{array}{l}1.992) \\
66\end{array}$ & .014 & $\begin{array}{l}2.445) \\
84\end{array}$ \\
\hline $\begin{array}{l}\text { Upper back } \\
\text { hunched } \\
E=18 \text {; unE }=22\end{array}$ & $\begin{array}{l}\text { Mean } \\
\text { SD }\end{array}$ & $\begin{array}{c}71 \\
(5.0 \\
)\end{array}$ & $\begin{array}{c}74 \\
(4.7 \\
) \\
\end{array}$ & $\begin{array}{c}-0.2 \\
(1.92)\end{array}$ & $\begin{array}{c}0.83 \\
(1.31)\end{array}$ & & & & \\
\hline $\begin{array}{l}\mathrm{p} \text { (Z-value) } \\
\text { ES }\end{array}$ & & $\begin{array}{l}.00 \\
3 . \\
-0\end{array}$ & & $\begin{array}{r}.042 \\
-\end{array}$ & $\begin{array}{l}-2.03) \\
68\end{array}$ & & & & \\
\hline
\end{tabular}

VHI-P = physical subscale of VHI, $\mathrm{SD}=$ standard deviation, $\mathrm{Z}=$ test statistic for Wilcoxon signedranks test $\mathrm{p}=$ probability value, $\mathrm{ES}=$ effect size. $\mathrm{N}=39-40$. 
Table 5. The effect of the number of unergonomic postures on teachers' voice symptoms. Groups using few $(\mathrm{F})$ or several unergonomic postures $(\mathrm{S})$ were compared with each other. Group sizes (n) are given in the first column.

\begin{tabular}{|c|c|c|c|c|c|c|c|}
\hline \multirow[t]{2}{*}{$\begin{array}{l}\text { Number of poor postures in } \\
\text { groups } F \text { and } S\end{array}$} & & \multicolumn{2}{|c|}{ VHI-P } & \multicolumn{2}{|c|}{$\begin{array}{l}\text { Difficulty in } \\
\text { audibility due } \\
\text { to voice }\end{array}$} & \multicolumn{2}{|c|}{ Voice breaks $^{1}$} \\
\hline & & $\mathrm{F}$ & $\mathrm{S}$ & $\mathrm{F}$ & $\mathrm{S}$ & $\mathrm{F}$ & $\mathrm{S}$ \\
\hline $\mathrm{F}: \leq 1$ posture $(\mathrm{n}=10)$ & Mean & 5.4 & 9.9 & & & & \\
\hline$S: \geq 2$ postures $(n=29)$ & $\mathrm{SD}$ & $(3.47)$ & $(6.24)$ & & & & \\
\hline $\mathrm{p}(\mathrm{Z}$-value $)$ & & \multicolumn{2}{|c|}{$.031(-2.16)$} & & & & \\
\hline ES & & \multicolumn{2}{|c|}{$-.0 .74$} & & & & \\
\hline $\mathrm{F}: \leq 2$ postures $(\mathrm{n}=18)$ & Mean & & & 1.7 & 2.3 & & \\
\hline$S: \geq 3$ postures $(n=21)$ & $\mathrm{SD}$ & & & $(1.0)$ & $(1.3)$ & & \\
\hline $\mathrm{p}(\mathrm{Z}$-value $)$ & & \multicolumn{6}{|c|}{$.04(-2.050)$} \\
\hline ES & & \multicolumn{6}{|c|}{-0.70} \\
\hline $\mathrm{F}: \leq 3$ postures $(\mathrm{n}=27)$ & Mean & & & & & 1.7 & 3 \\
\hline$S: \geq 4$ postures $(n=12)$ & $\mathrm{SD}$ & & & & & $(0.9)$ & $(1.28)$ \\
\hline $\mathrm{p}$ (Z-value) & & & & & & .011 & $2.557)$ \\
\hline $\mathrm{ES}$ & & & & & & & \\
\hline
\end{tabular}

VHI-P = physical subscale of VHI (range of scores $0-40$ ), , SD=standard deviation, $\mathrm{Z}=$ test statistic for Wilcoxon signed-ranks test, $\mathrm{p}=$ probability value, $\mathrm{ES}=$ effect size. $\mathrm{N}=39-40$.

${ }^{1}$ Range of scores for specific voice symptoms $0-4$ 
Table 6. The effect of the number of unergonomic postures on teachers' voices. Group using few (F) or several unergonomic postures (S) were compared with each other. Group sizes (n) are given in the first column.

\begin{tabular}{|c|c|c|c|c|c|c|c|c|}
\hline \multirow{3}{*}{$\begin{array}{l}\text { Number of poor } \\
\text { postures in } \\
\text { groups } \mathrm{F} \text { and } \mathrm{S}\end{array}$} & \multicolumn{4}{|c|}{ Before and after a working day } & \multicolumn{4}{|c|}{ During lessons } \\
\hline & \multicolumn{2}{|c|}{ SPL before } & \multicolumn{2}{|c|}{ SPL after } & \multicolumn{2}{|c|}{$\mathrm{F}_{0}$ change } & \multicolumn{2}{|c|}{ SPL change } \\
\hline & $\mathrm{F}$ & $\mathrm{S}$ & $\mathrm{F}$ & $\mathrm{S}$ & $\mathrm{F}$ & $\mathrm{S}$ & $\mathrm{F}$ & $\mathrm{S}$ \\
\hline $\mathrm{F}: \leq 1$ posture $(\mathrm{n}=11)$ & 70 & 73 & & & 18 & 2 & 3 & -1 \\
\hline$S: \geq 2$ postures $(n=28-29)$ & $(5.0)$ & $(4.8)$ & & & $(10.5)$ & $(19.3)$ & $(5.0)$ & $(6.8)$ \\
\hline $\mathrm{p}$ & \multicolumn{2}{|c|}{$.05(-1.961)$} & & & \multicolumn{2}{|c|}{$.008(-2.65)$} & \multicolumn{2}{|c|}{$.044(-2.014)$} \\
\hline ES & \multicolumn{2}{|c|}{-0.71} & & & \multicolumn{2}{|c|}{1.05} & \multicolumn{2}{|c|}{0.62} \\
\hline $\mathrm{F}: \leq 2$ postures $(\mathrm{n}=19)$ & 70 & 74 & 71 & 74 & & & & \\
\hline$S: \geq 3$ postures $(n=20-21)$ & $(4.8)$ & $(4.8)$ & $(4.2)$ & (3.6) & & & & \\
\hline $\mathrm{p}$ & \multicolumn{2}{|c|}{$.023(-2.27)$} & \multicolumn{2}{|c|}{$.043(-2.023)$} & & & & \\
\hline ES & \multicolumn{2}{|c|}{-0.83} & \multicolumn{2}{|c|}{-0.77} & & & & \\
\hline F: $\leq 3$ postures $(n=27-28)$ & 71 & 76 & 72 & 75 & & & & \\
\hline$S: \geq 4$ postures $(n=12)$ & $(4.9)$ & $(4.4)$ & (4.4) & $(2.3)$ & & & & \\
\hline $\mathrm{p}$ & .003 & 947) & .033 & $.129)$ & & & & \\
\hline ES & & & & & & & & \\
\hline
\end{tabular}

VHI-P = physical subscale of VHI, $\mathrm{SD}=$ standard deviation, $\mathrm{Z}=$ test statistic for Wilcoxon signedranks test , $\mathrm{p}=$ probability value, $\mathrm{ES}=$ effect size. $\mathrm{N}=39-40$. 

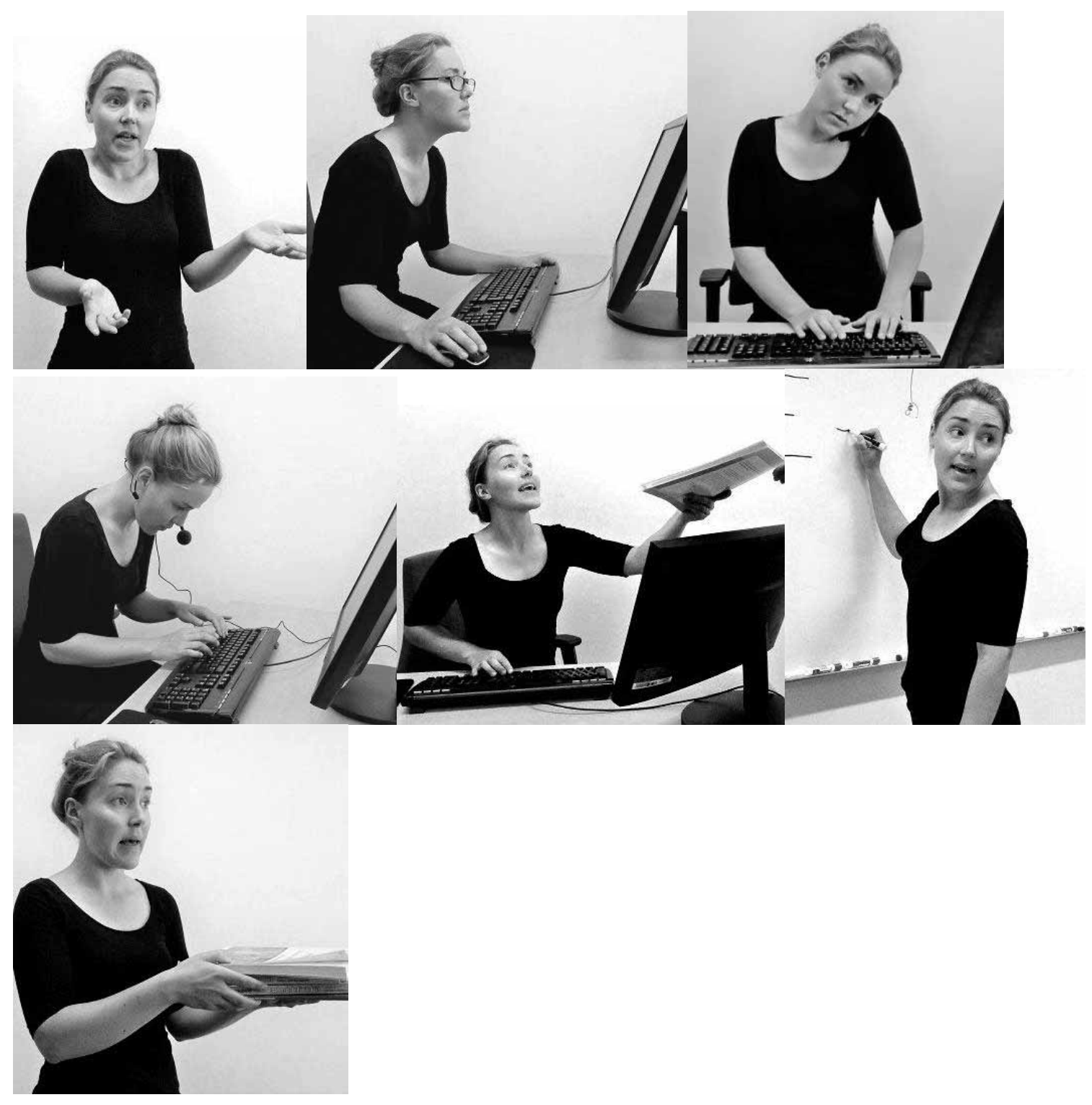

Figure 1. Unergonomic working postures while speaking: torso twisted to the side and head turned (photo 1), head/chin thrust forward (photo 2), head/chin thrust downwards (photo 3), head tilted toward the shoulder (4), unergonomic head/neck posture due to varifocal glasses (photo 5), upper back hunched (photo 3); shoulders raised/tense (photo 6); arms raised while holding things in the hands (photo 7) (photo: E. Sala(C). 


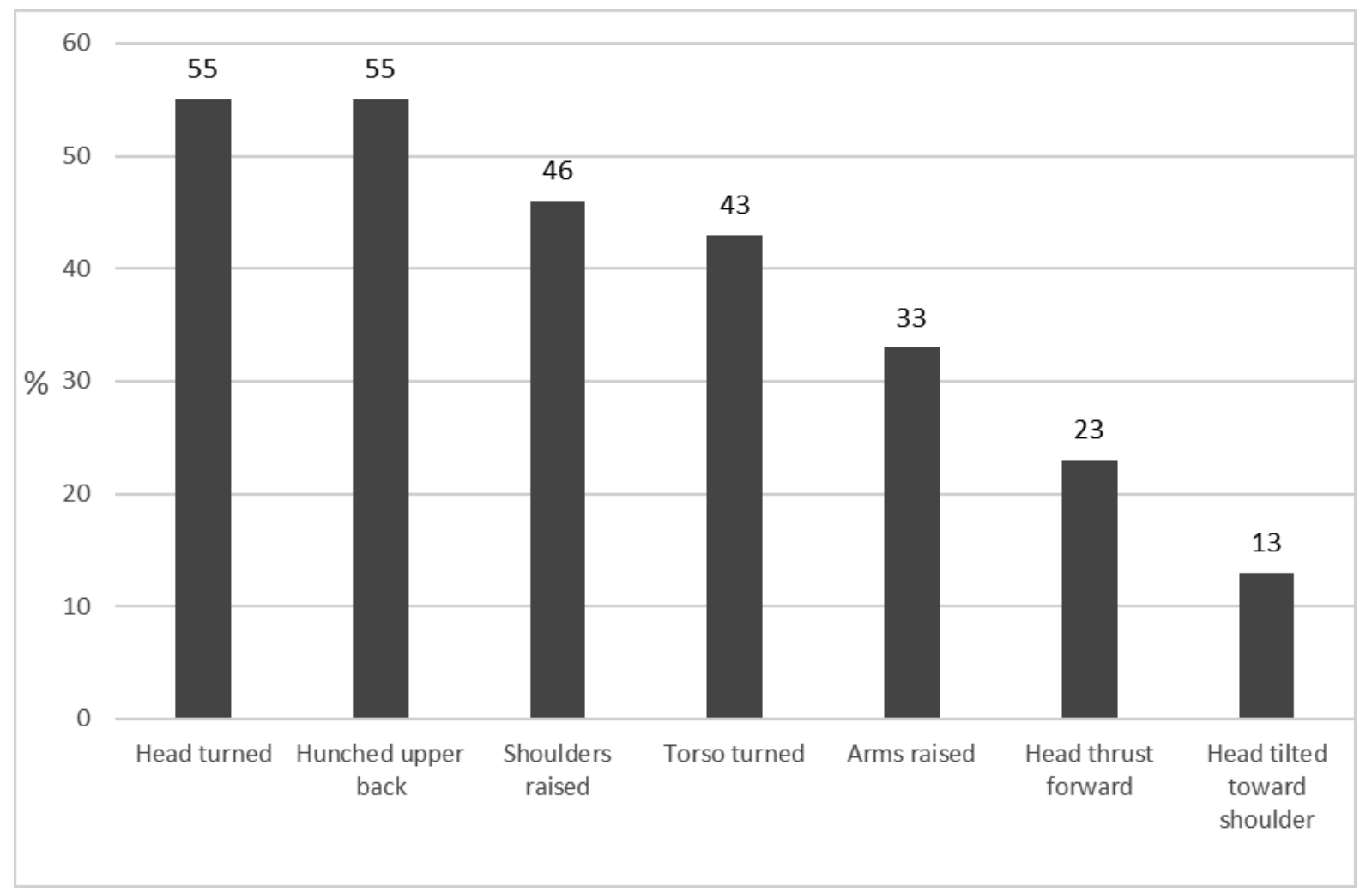

Figure 2. Participants' most typical working postures while talking in class. $\mathrm{N}=40$. 